\title{
Using Averaged Modeling for Capacitors Voltages Observer in NPC Inverter
}

\author{
Bassem Omri, Kaiçar Ammous, and Anis Ammous \\ Power Electronics Group, Université de Sfax, ENIS-Sfax, BP. 1173, 3038 Sfax, Tunisia \\ Correspondence should be addressed to Bassem Omri, omri_bessem@yahoo.fr \\ Received 17 May 2012; Accepted 12 November 2012 \\ Academic Editor: C. M. Liaw
}

Copyright () 2012 Bassem Omri et al. This is an open access article distributed under the Creative Commons Attribution License, which permits unrestricted use, distribution, and reproduction in any medium, provided the original work is properly cited.

This paper developed an adaptive observer to estimate capacitors voltages of a three-level neutral-point-clamped (NPC) inverter. A robust estimated method using one parameter is proposed, which eliminates the voltages sensors. An averaged modeling of the inverter was used to develop the observer. This kind of modeling allows a good trade-off between simulation cost and precision. Circuit model of the inverter (implemented in Simpower Matlab simulator) associated to the observer algorithm was used to validate the proposed algorithm.

\section{Introduction}

Multilevel inverters can provide an effective alternative of high power applications, providing a high quality voltage, increasing efficiency and robustness, and reducing interference electromagnetics [1-4]. There are three main topologies of multilevel inverters: diode-clamped inverter $[2,5,6]$, flying capacitor inverter $[7,8]$, and cascade multilevel inverter $[6,9]$. Among the multilevel inverters, the most popular topology is the diode-clamped inverter which is called as a neutral-point-clamped (NPC) inverter in three levels. It is proposed by Nabae et al. [10]. This type of inverter avoids the complexity associated with the series connection of semiconductor switches or the bulky coupling transformer, produces low distortion harmonics, and has an average cost.

However, in NPC inverter, the DC-link voltage is divided by capacitors, and each capacitor is composed of series connection construction. Therefore, if the voltage unbalancing occurs between each capacitor, the line-to-line output voltage waveform has many harmonic components and the power devices in NPC inverter cannot guarantee the safe operation. So, one NPC inverter requirement is to produce a good control maintaining the optimal balance of capacitor voltages [11-13]. Thus, regulation of these capacitors voltages requires information about such voltages.
For that there are two possibilities either measuring or estimating such voltages.

Regarding the first possibility, it presents several disadvantages: besides the known difficulties when measuring a high-voltage level, if the number of levels increases the number of capacitors increases in NPC inverter. Then it will be necessary to use multiple-voltage sensors to measure the capacitor voltages, which reduces the reliability. Furthermore, the use of the voltages sensors presents many difficulties of establishment in front of the use of the current sensors. On the other hand, the second alternative uses software sensors, called observers, which replace the physical sensors (the voltage sensors). It is suitable to estimate the capacitors voltages through only the phase currents measurement. So, the observer is independent of the number of the level of NPC inverter. Unlike the traditional direct voltage sensing depends on the levels number.

An observer is a data-processing algorithm to reconstruct the variable state system from the input, mathematical model, and output measurement of the real system. It is an attractive solution because it benefits from a mathematical model of the system. It is less expensive and more reliable because it is applied by a digital computer. Actually, the calculation of the digital signal processors (DSP) is the execution of such sophisticated and complex algorithms 


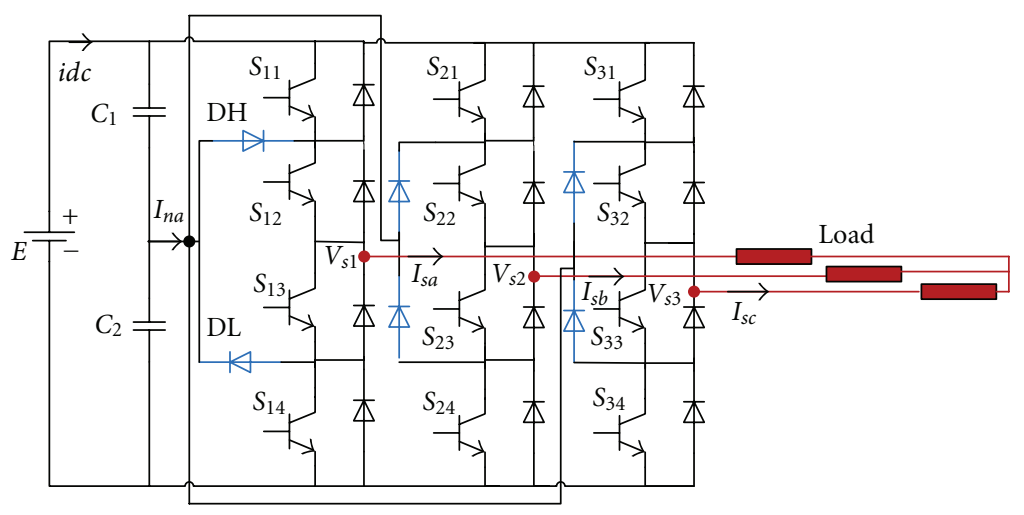

Figure 1: A 3-level NPC converter topologies.

with the high-degree precision. Many works related to the observer design for the nonlinear systems were published [14-16].

Recently, the authors [17] designed a robust observer based on adaptive backstepping approach for three-level NPC inverters. It is used for capacitor voltages estimation. This approach gave good results. However, the authors used an instantaneous reference model of NPC inverter. Therefore, the simulation cost is significant. Moreover, the adaptive backstepping algorithm used many parameters (adaptation gains, design constant) to design the observer. The algorithm becomes so complex when the number of levels increases.

This paper proposes an adaptive observer in order to estimate the voltages capacitors of 3-levels inverter NPC (Figure 1). The adapive algorithm is robust, simple to implement, and uses one parameter called forgetting factor. An averaged reference model of three-level NPC inverter is used for simulation. This kind of modeling allows a good tradeoff between simulation cost and precision.

This paper is organized as follows. In Section 2, the PWM control strategies are presented. An averaged reference model of three-level inverter NPC is given in Section 3. Section 4 shows the observer design for the NPC inverter. Finally, simulation results are given in order to illustrate the performance of the proposed observer to estimate NPC capacitors voltages.

\section{The PWM Control Strategies of Multilevel Inverters}

The proliferation of power electronic devices has led to a demand for more effective pulse width modulation strategies. The current waveform can be improved by increasing the frequency of the carrier wave; this approach reduces copper losses at the expense of increased switching losses. To overcome the limitations of existing switching strategies the technique known as space vector pulse width modulation (SVPWM) is becoming widely used in industry $[18,19]$.

SVPWM is a highly efficient method of generating the six-pulsed signals for the inverter stage of the motor drive. Conventional switching techniques treat each phase as a separately generated sinusoid that is displaced by 120 degrees. However, a change in the voltage of one-half bridge due to switching invariably influences the other two-phase voltages [20]. SVPWM evaluates the switching schema as a whole, which results in better use of the DC bus and generates significantly less harmonic distortion than the sine triangle method [20].

The SVPWM control of the 3-level NPC inverter consists to control it in the $(\alpha, \beta)$ coordinates which can generate 27 possible voltages vectors (Figure 2). They are divided in 6 large vectors (PNN,PPN,NPN,NPP,NNP,PNP), 6 medium vectors (PON,OPN,NPO,NOP,ONP,PNO), 12 small vectors (with the redundancy: (PPO,OON), (OPO,NON), (OPP,NOO), (OOP,NNO), (ONO,POP), (POO,ONN)) and 3 zero vectors (OOO,NNN,PPP). When the power devices, $S_{k 1}$ and $S_{k 2}$, are connected to the positive DC-link rail the state is noted by "P." In contrast, when the output is connected to the negative DC-rail by turning both $S_{k 3}$ and $S_{k 4}$ on, the state is called "N." Moreover, the switching state is defined as "O" when $S_{k 2}$, and $S_{k 3}$ both power devices, are on.

The objective of SVPWM technique is to approximate a reference space vector $V_{s}$ somewhere within the hexagon of Figure 2 using a combination of the 27 switching vectors. Indeed, when the reference voltage is in one sector, several couples of vector are possible.

For example in Sector 1 (Figure 3), the $V_{s}$ vector can be divided on $V_{1 a}, V_{12}$ or $V_{1 b}, V_{12}$. We choose the second solution, since $V_{1 b}$ is greater in amplitude than $V_{1 a}$. At each commutation period of the inverter, the vector $V_{s}$, projected on two adjacent vectors, ensures the calculation of the dwelling time.

Let $T_{\bmod }$ be a modulation period, $T_{1 b}$ dwelling time of the first vector $V_{1 b}, T_{12}$ dwelling time of the second vector $V_{12}$, and $T_{\text {nul }}=T_{\text {mod }}-T_{1 b}-T_{12}$ dwelling time of zero vectors. We define the duty cycles $\rho_{1}$ and $\rho_{2}$ related to times $T_{1 b}$ and $T_{12}$, respectively, of the vectors $V_{1 b}$ and $V_{1 a}$ by:

$$
\rho_{1}=\frac{T_{1}}{T_{\text {mod }}}, \quad \rho_{2}=\frac{T_{12}}{T_{\text {mod }}} .
$$

For one modulation period $T_{\text {mod }}$, the output voltage of the inverter is given by:

$$
T_{\bmod } V_{S}=\left(T_{1 b} V_{1 b}+T_{12} V_{12}+T_{3} V_{\text {Null }}\right) .
$$




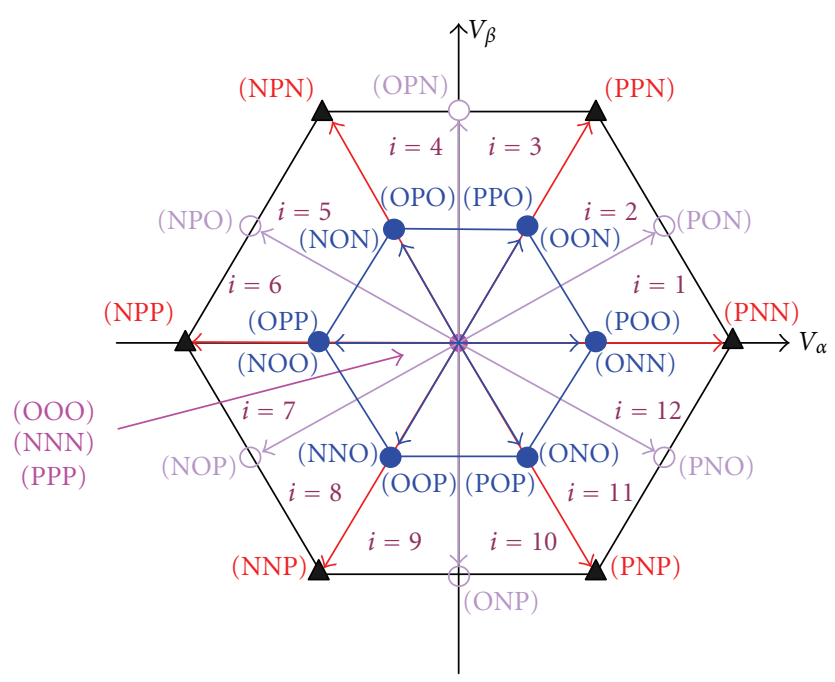

FIGURE 2: Voltage space vectors in NPC inverter.

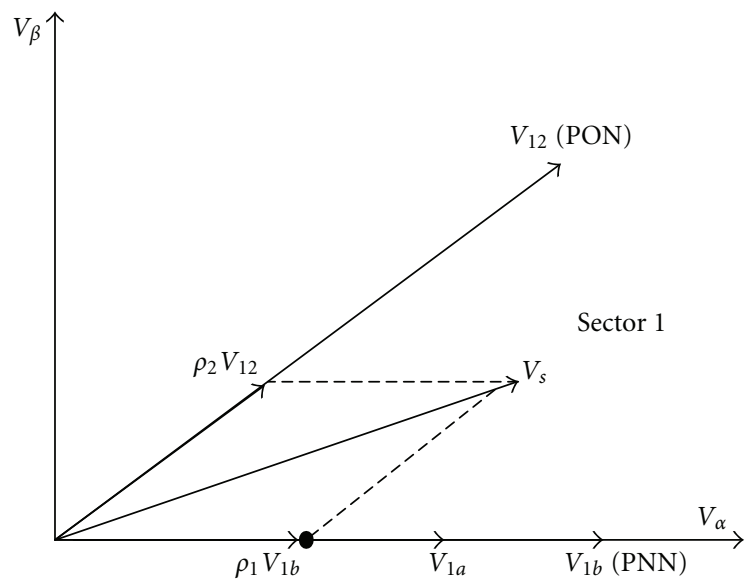

Figure 3: Sector 1.

And the dwelling time of each vector is given by

$$
\begin{gathered}
T_{1 b}=\frac{2 \sqrt{3} T_{\text {mod }}}{E}\left(\frac{1}{2 \sqrt{2}} V_{s \alpha}-\frac{\sqrt{3}}{2 \sqrt{2}} V_{s \beta}\right), \\
T_{12}=\frac{2 \sqrt{2} T_{\text {mod }}}{E} V_{s \beta} . \\
T_{\text {null }}=T_{\text {mod }}-T_{12}-T_{1 b} .
\end{gathered}
$$

For more details see [21].

\section{The Nonideal Average Model}

Based on the averaged representation of the PWM switch [22], Figure 4 shows the proposed averaged model of the one-leg three-level multilevel converters. $I_{s a}$ is the average value of the load current over the switching period. This model applies a controlled voltage source $\left(V_{a 1}\right.$ and $\left.V_{a 2}\right)$ and a controlled current source $\left(I_{a 1}\right.$ and $\left.I_{a 2}\right)$. Each three-level converter leg has four controlled switches and six uncontrolled switches. The four controlled switches are directly governed

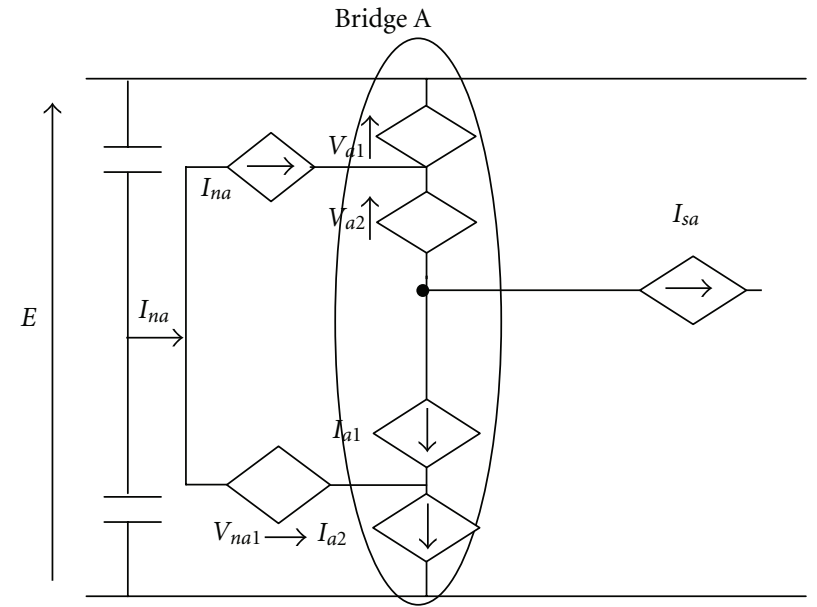

Figure 4: The proposed average model of the 3-level PWM converter.

by external control signals. The uncontrolled switches are indirectly governed by the state of the controlled switches and the circuit conditions.

The average values of the different voltage and current sources of the proposed averaged model of the bridge (A) are given by [22].

Consider that $T_{\text {mod }}$ is the switching period of the active switch and $\rho\left(\rho_{1}, \rho_{2}, \rho_{3}\right)$ the duty cycle, which is the ratio of the on-time of the active couple switches $\left(\left(S_{i 1}, S_{i 2}\right),\left(S_{i 2}\right.\right.$, $\left.S_{i 3}\right)$, or $\left.\left(S_{i 3}, S_{i 4}\right)\right)$ by the switching period $T_{\text {mod }}$, respectively (Figure 5).

$V_{d}$ and $V_{d s}$ represent respectively, the voltage across the diode and the MOSFET in on-state. These values can be deduced from the devices static characteristics $I(V)$ :

$$
\begin{gathered}
\rho_{i}=\frac{T_{\text {on } i}}{T_{p w m}} ; \quad \rho_{M i}=\frac{T_{\text {off } i}}{T_{p w m}}, \\
\rho_{M}=\rho_{M 1}+\rho_{M 2}+\rho_{M 3} .
\end{gathered}
$$

When only output current behavior is considered, a simplified representation of the averaged model (Figure 6) can be used, where

$$
\begin{gathered}
\left\langle I_{n a}\right\rangle=\left(I_{n a 1}+I_{a 2}-I_{a 1}\right), \\
\left\langle V_{a}\right\rangle=\left(V_{a 1}+V_{a 2}\right), \\
\left\langle I_{a}\right\rangle=\left\langle I_{a 2}\right\rangle .
\end{gathered}
$$

The averaged values of the voltage source $V_{a}$ and the current source $I_{a}$ of the bridge (A) are given as follows.

If the current $I_{s a}$ is positive,

$$
\begin{gathered}
\left\langle V_{a}\right\rangle=2 V d s \rho_{1}+(E+2 V d) \rho_{3} \\
+\left(\frac{E}{2}+V d+V d s\right) \rho_{2}+(E+2 V d) \rho_{M}, \\
\left\langle I_{a}\right\rangle=-I_{s a} \rho_{3} \\
\left\langle I_{n a}\right\rangle=I_{s a} \rho_{2} .
\end{gathered}
$$




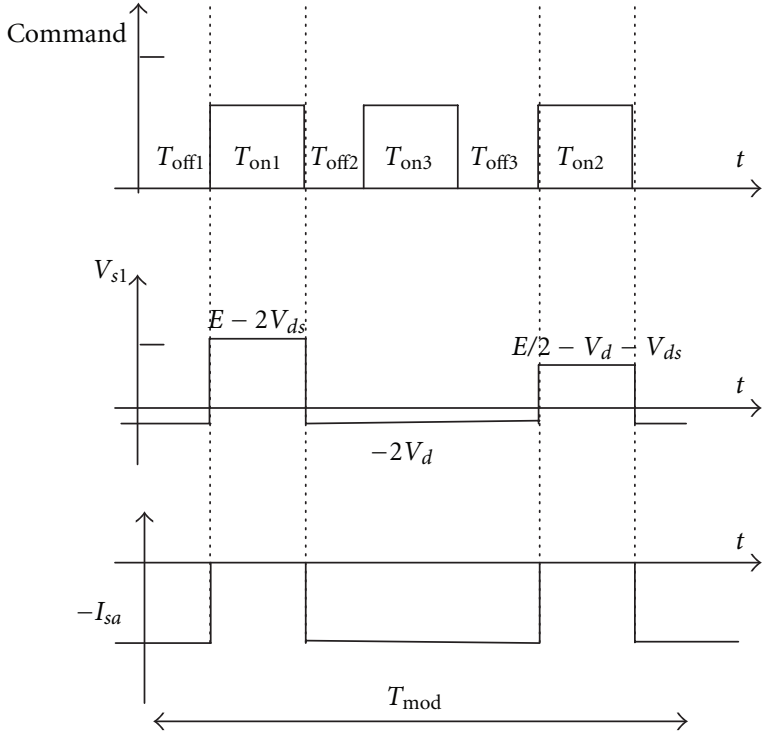

Figure 5: Command signals of the controlled devices in the case of $I_{s a}>0$.

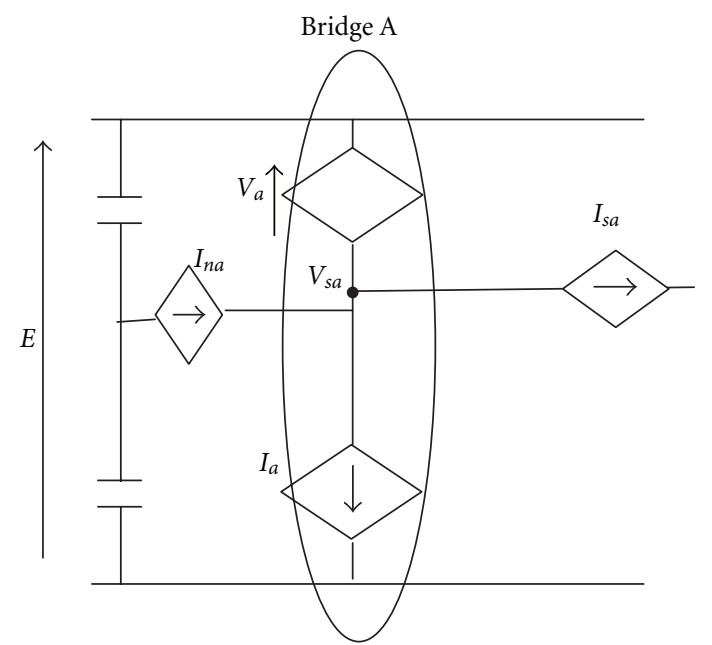

FIGURE 6: A simplified representation of averaged model.

If the current $I_{s a}$ is negative,

$$
\begin{aligned}
&\left\langle V_{a}\right\rangle=-2 V d \rho_{1}+(E-2 V d s) \rho_{3} \\
&+\left(\frac{E}{2}-V d-V d s\right) \rho_{2}+(2 V d) \rho_{M}, \\
&\left\langle V_{a}\right\rangle=-2 V d \rho_{1}+(E-2 V d s) \rho_{3} \\
&+\left(\frac{E}{2}-V d-V d s\right) \rho_{2}+(2 V d) \rho_{M}, \\
&\left\langle I_{a}\right\rangle=I_{s a} \rho_{3} .
\end{aligned}
$$

In order to demonstrate the accuracy of the proposed averaged model, a circuit model of the inverter implemented in Simpower Matlab simulator, using the circuit represented in Figure 1 is used. For the simulation in this section and

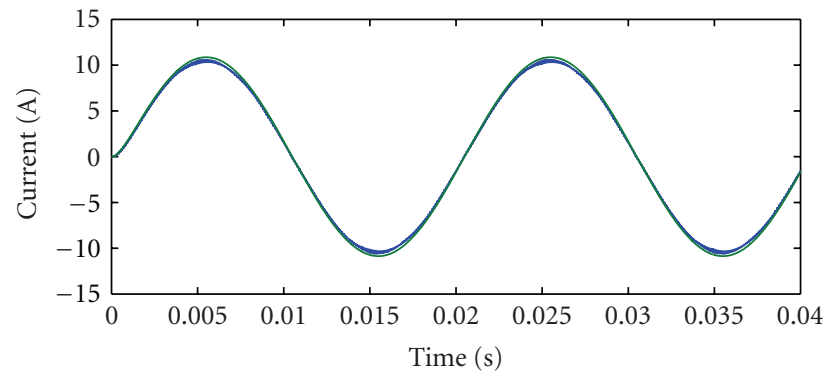

FIGURE 7: The output current obtained with the non-ideal averaged model and the circuit model after filtering (3-levels converter).

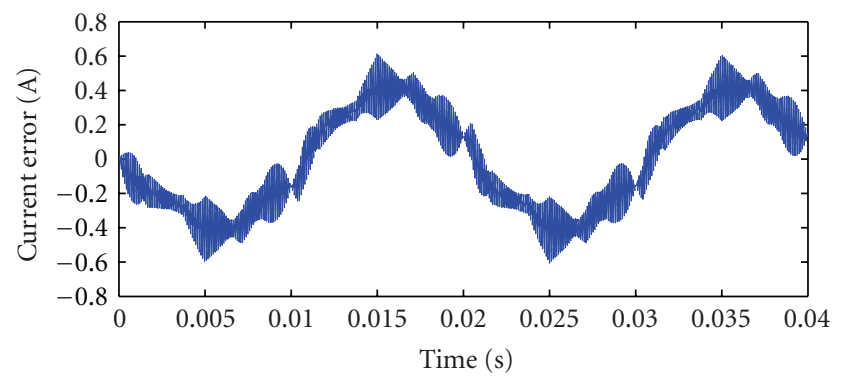

FIGURE 8: The current error.

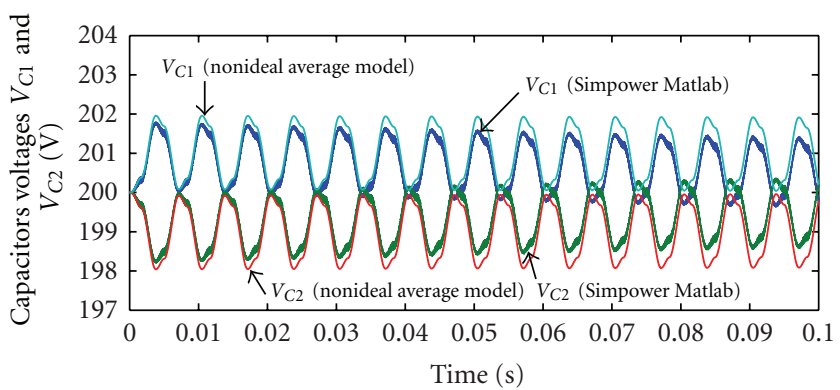

Figure 9: Evolution of the capacitors voltages $C_{1}$ and $C_{2}$ (using Simpower Matlab and the averaged model).

Section 5, we use $2 \mathrm{GHz}$ Core2 Duo processor and $3 \mathrm{~GB}$ RAM.

The comparison between the current waveforms (Figure 7) obtained by the Simpower simulator and the current given by the proposed model shows the good accuracy of the averaged model behavior for converter electric analysis. The current error between the two types' models is given in Figure 8.

Figure 9 shows the capacitors voltages $\left(C_{1}\right.$ and $\left.C_{2}\right)$ waveforms obtained by the model Simpower simulator and the averaged model. The simulation results given by the proposed averaged model are in good agreement with Simpower simulations.

It is evident that multilevel converter analysis using fine models gives accurate results, but these simulations cost is unaffordable. When long time range simulation is needed, the proposed averaged model can be used, and the obtained results show the accuracy of the proposed model (Table 1). 
TABLE 1: CPU running time (s) necessary to simulate a period (0.02s).

\begin{tabular}{lc}
\hline Type model & Running time $(\mathrm{s})$ \\
\hline Nonideal averaged model & 10 \\
Circuit model (Simpower Matlab) & 90 \\
\hline
\end{tabular}

So, we used this model like a reference model in the observer design.

\section{Observer Design of Capacitors Voltages}

The DC side of the three-level NPC inverter (Figure 1) has a DC source $E$ and two connections capacitors $C_{1}$ and $C_{2}$. The switching variable $\gamma_{k}$ represents the state of the multilevel inverter active switches, $S_{k j}, k \in\{1,2,3\}, j \in\{1,2,3,4\}$. The three states of the binary switching $\gamma_{k}$ can be defined as

$$
\gamma_{k}= \begin{cases}1 & \left(S_{k 1}=1 \wedge S_{k 2}=1\right) \wedge\left(S_{k 3}=0 \wedge S_{k 4}=0\right) \\ 0 & \left(S_{k 1}=0 \wedge S_{k 2}=1\right) \wedge\left(S_{k 3}=1 \wedge S_{k 4}=0\right) \\ -1 & \left(S_{k 1}=0 \wedge S_{k 2}=0\right) \wedge\left(S_{k 3}=1 \wedge S_{k 4}=1\right) .\end{cases}
$$

Applying the Kirchhoff laws to the three-level inverter circuit (Figure 1) and doing some mathematical manipulations, the dynamic equations of the AC currents, $I_{s a}, I_{s b}$, and $I_{s c}$, and the capacitor voltages, $V_{C 1}$ and $V_{C 2}$, are defined as functions of the circuit parameters and switching variables $\gamma_{k}$ :

$$
\begin{aligned}
& {\left[\begin{array}{c}
\frac{d I_{s a}}{d t} \\
\frac{d I_{s b}}{d t} \\
\frac{d I_{s c}}{d t} \\
\frac{d V_{C 1}}{d t} \\
\frac{d V_{C 2}}{d t}
\end{array}\right]=\left[\begin{array}{ccccc}
-\frac{R}{L} & 0 & 0 & \frac{\psi_{11}}{L} & \frac{\psi_{12}}{L} \\
0 & -\frac{R}{L} & 0 & \frac{\psi_{21}}{L} & \frac{\psi_{22}}{L} \\
0 & 0 & -\frac{R}{L} & \frac{\psi_{31}}{L} & \frac{\psi_{31}}{L} \\
-\frac{\Gamma_{11}}{C_{1}} & -\frac{\Gamma_{12}}{C_{1}} & -\frac{\Gamma_{13}}{C_{1}} & 0 & 0 \\
-\frac{\Gamma_{21}}{C_{2}} & -\frac{\Gamma_{22}}{C_{2}} & -\frac{\Gamma_{23}}{C_{2}} & 0 & 0
\end{array}\right]} \\
& \times\left[\begin{array}{c}
I_{s a} \\
I_{s b} \\
I_{s c} \\
V_{C 1} \\
V_{C 2}
\end{array}\right]+\left[\begin{array}{c}
0 \\
0 \\
0 \\
\frac{1}{C_{1}} \\
\frac{1}{C 2}
\end{array}\right] \times i d c, \\
& \Gamma_{1 k}=\frac{\gamma_{k}\left(\gamma_{k}+1\right)}{2}, \quad \Gamma_{2 k}=\frac{\gamma_{k}\left(-\gamma_{k}+1\right)}{2} \text {, } \\
& \psi_{k i}=\frac{1}{3}\left(2 \Gamma_{i k}-\sum_{j=1, j \neq k}^{3} \Gamma_{i k}\right) .
\end{aligned}
$$

In order to obtain a simplified model which contains less equations, we change the switching sequences in the $(\alpha, \beta)$ coordinates:

$$
X_{123}=[T] X_{\alpha \beta}
$$

where $T$ is the Concordia transformation:

$$
T=\frac{\sqrt{2}}{\sqrt{3}}\left(\begin{array}{cc}
1 & 0 \\
-\frac{1}{2} & \frac{\sqrt{3}}{2} \\
-\frac{1}{2} & -\frac{\sqrt{3}}{2}
\end{array}\right) .
$$

Applying (11) to (8), the new model is represented in $(\alpha, \beta)$ coordinates by

$$
\begin{aligned}
{\left[\begin{array}{c}
\frac{d I_{\alpha}}{d t} \\
\frac{d I_{\beta}}{d t} \\
\frac{d V_{C 1}}{d t} \\
\frac{d V_{C 2}}{d t}
\end{array}\right]=\left[\begin{array}{cccc}
-\frac{R}{L} & 0 & \frac{\Gamma_{1 \alpha}}{L} & \frac{\Gamma_{2 \alpha}}{L} \\
0 & -\frac{R}{L} & \frac{\Gamma_{1 \beta}}{L} & \frac{\Gamma_{2 \beta}}{L} \\
-\frac{\Gamma_{1 \alpha}}{C_{1}} & -\frac{\Gamma_{1 \beta}}{C_{1}} & 0 & 0 \\
-\frac{\Gamma_{2 \alpha}}{C_{2}} & -\frac{\Gamma_{2 \beta}}{C_{2}} & 0 & 0
\end{array}\right] } \\
\times\left[\begin{array}{c}
I_{\alpha} \\
I_{\beta} \\
V_{C 1} \\
V_{C 2}
\end{array}\right]+\left[\begin{array}{c}
0 \\
0 \\
\frac{1}{C_{1}} \\
\frac{1}{C_{2}}
\end{array}\right] \times i d c,
\end{aligned}
$$

where

$$
\Gamma_{i \alpha}=\frac{\sqrt{2}}{\sqrt{3}}\left(\Gamma_{i 1}-\frac{\Gamma_{i 2}}{2}-\frac{\Gamma_{i 3}}{2}\right), \quad \Gamma_{i \beta}=\frac{1}{\sqrt{2}}\left(\Gamma_{i 2}-\Gamma_{i 3}\right) .
$$

This model can be written as

$$
\begin{gathered}
\dot{X}=A(S) X+H(S, X), \\
y=C X,
\end{gathered}
$$

where $X=\left(\begin{array}{llll}I_{\alpha} & I_{\beta} & V_{C 1} & V_{C 2}\end{array}\right)^{T}, C=\left(\begin{array}{llll}1 & 1 & 0 & 0\end{array}\right), H(S, X)=$ $\left[\begin{array}{c}0 \\ 0 \\ 1 / C_{1} \\ 1 / C_{2}\end{array}\right]$

$$
A(S)=\left[\begin{array}{cccc}
-\frac{R}{L} & 0 & \frac{\Gamma_{1 \alpha}}{L} & \frac{\Gamma_{2 \alpha}}{L} \\
0 & -\frac{R}{L} & \frac{\Gamma_{1 \beta}}{L} & \frac{\Gamma_{2 \beta}}{L} \\
-\frac{\Gamma_{1 \alpha}}{C_{1}} & -\frac{\Gamma_{1 \beta}}{C_{1}} & 0 & 0 \\
-\frac{\Gamma_{2 \alpha}}{C_{2}} & -\frac{\Gamma_{2 \beta}}{C_{2}} & 0 & 0
\end{array}\right] .
$$

For different configurations, the capacitors are not always traversed by the load current. The current can pass by one or two capacitors as it cannot traverse any capacitor if the top 
switchers of each leg are all closed or all open. Thus, some configurations give observability problem of the studied system. This can be proven by the test of rank, whenever, at least, a capacitor is traversed by the load current:

$$
\Theta=\operatorname{rang}\left(\left[\begin{array}{c}
C \\
C A \\
C A^{2} \\
C A^{3}
\end{array}\right]\right)=3 \prec 4 .
$$

It is clear that $\Theta$ is not of full rank; thus the system is not observable. So, to design the observer, a convenient representation of the model must be given.

To overcome this difficulty, the idea is to consider two interconnected affine models and to construct the new observer based on those models.

Now, consider that the system (15) can be represented as a set of the interconnected subsystems as follows:

$$
\begin{aligned}
& \Sigma_{1}:\left[\begin{array}{c}
\frac{d I_{\alpha}}{d t} \\
\frac{d I_{\beta}}{d t} \\
\frac{d V_{C 1}}{d t}
\end{array}\right]=\left[\begin{array}{ccc}
-\frac{R}{L} & 0 & \frac{\Gamma_{1 \alpha}}{L} \\
0 & -\frac{R}{L} & \frac{\Gamma_{1 \beta}}{L} \\
-\frac{\Gamma_{1 \alpha}}{C_{1}} & -\frac{\Gamma_{1 \beta}}{C_{1}} & 0
\end{array}\right]\left[\begin{array}{c}
I_{\alpha} \\
I_{\beta} \\
V_{C 1}
\end{array}\right] \\
& +\left[\begin{array}{c}
\frac{\Gamma_{2 \alpha}}{L} \\
\frac{\Gamma_{2 \beta}}{L} \\
0
\end{array}\right] V_{C 2}+\left[\begin{array}{c}
0 \\
0 \\
\frac{1}{C_{1}}
\end{array}\right] \times i d c, \\
& \Sigma_{2}:\left[\begin{array}{c}
\frac{d I_{\alpha}}{d t} \\
\frac{d I_{\beta}}{d t} \\
\frac{d V_{C 2}}{d t}
\end{array}\right]=\left[\begin{array}{ccc}
-\frac{R}{L} & 0 & \frac{\Gamma_{2 \alpha}}{L} \\
0 & -\frac{R}{L} & \frac{\Gamma_{2 \beta}}{L} \\
-\frac{\Gamma_{2 \alpha}}{C_{2}} & -\frac{\Gamma_{2 \beta}}{C_{2}} & 0
\end{array}\right]\left[\begin{array}{c}
I_{\alpha} \\
I_{\beta} \\
V_{C 2}
\end{array}\right] \\
& +\left[\begin{array}{c}
\frac{\Gamma_{1 \alpha}}{L} \\
\frac{\Gamma_{1 \beta}}{L} \\
0
\end{array}\right] V_{C 1}+\left[\begin{array}{c}
0 \\
0 \\
\frac{1}{C_{2}}
\end{array}\right] \times i d c .
\end{aligned}
$$

Each subsystem can be written as

$$
\Sigma_{j}\left\{\begin{array}{l}
\dot{\chi}_{j}=A_{j}\left(S_{k}\right) \chi_{j}+\Gamma_{i}\left(S_{k}, \chi_{j}\right), \\
y=C_{j} \chi_{j}, \quad j=1,2 k=1,2,3 i=1,2 \neq j
\end{array}\right.
$$

where $\chi_{j}=\left(\begin{array}{llll}I_{\alpha} & I_{\beta} & V_{C j}\end{array}\right)^{T}$ represents the state of the $j$ th subsystem, $S_{k}$ are the instantaneous inputs applied to the system, and $y$ is the measurable output, and

$$
\begin{gathered}
A_{j}\left(S_{k}\right)=\left[\begin{array}{ccc}
-\frac{R}{L} & 0 & \frac{\Gamma_{j \alpha}}{L} \\
0 & -\frac{R}{L} & \frac{\Gamma_{j \beta}}{L} \\
-\frac{\Gamma_{j \alpha}}{C_{j}} & -\frac{\Gamma_{j \beta}}{C_{j}} & 0
\end{array}\right], \\
\Gamma_{i}\left(S_{k}, \chi_{j}\right)=\left[\begin{array}{c}
\frac{\Gamma_{i \alpha}}{L} \\
\frac{\Gamma_{i \beta}}{L} \\
0
\end{array}\right] V_{C i}+\left[\begin{array}{c}
0 \\
\frac{1}{C_{j}}
\end{array}\right] \times i d c, \\
j=1,2, \quad k=1,2,3, \quad i=1,2 \neq j,
\end{gathered}
$$

and $C=\left(\begin{array}{lll}1 & 1 & 0\end{array}\right)$.

The function $\Gamma_{i}\left(S_{k}, \chi_{j}\right)$ is the interconnection function. It depends on the control $S_{k}$ and the state vector of each subsystem $\Sigma_{j}$.

From the preceding composition (22), the following system:

$$
\varphi_{j}\left\{\begin{array}{l}
Z_{j}=A_{j}\left(S_{k}\right) Z_{j}+\Gamma_{i}\left(S_{k}\right)-P_{j}^{-1} C_{j}(y-\hat{y}), \\
P_{j}=-\theta_{j} P_{j}-A^{T}\left(S_{k}\right) P_{j}-P_{j} A\left(S_{k}\right)+C_{j} C_{j}^{T},
\end{array}\right.
$$

is an observer for the system (16) for $j=1,2$, where $P_{j}^{-1} C_{j}$ is the observer gain which depends on the solution of the Riccati equation (25) for each subsystem $\Sigma_{j}$. The parameter $\theta_{j}$ must be a positive constant and sufficiently greater such that for any positive symmetric matrix $P_{j}(0)$, the following condition is verified [23]:

$$
\begin{gathered}
\forall \theta \geq \theta_{0} \quad \exists \gamma \succ 0, \delta \succ 0, t_{0} \succ 0: \forall t \geq t_{0}, \\
\gamma I \leq P(0) \leq \delta I .
\end{gathered}
$$

The parameter $\theta_{j}$ determines the convergence rate of the observer. The authors [23] proposed guidelines for the tuning of the parameters of the adaptive observer.

Note that this observer is the deterministic version of the Kalman filter for state affine systems. It is clear that the system observability depends on the applied inputs. Then the convergence of this observer can be proved assuming that the inputs $S_{j}$ are regularly persistent (see Appendix A); it is a class of admissible inputs that allows to observe the system (for more details, see [19]). This guarantees the works of observer, and the observer gain is well defined, that is, the matrix $P_{j}$ is nonsingular.

Now, a further result based on regular persistence is introduced.

Lemma 1. Assume that the input $S_{j}$ is regularly persistent for system (22) and consider the following Lyapunov differential equation:

$$
\dot{P}_{j}=-\theta_{j} P_{j}-A_{j}^{T}\left(S_{k}\right) P_{j}-P_{j} A_{j}\left(S_{k}\right)+C_{j} C_{j}^{T} .
$$


With $P_{j} \succ 0$, then, $\exists \theta_{j 0} \succ 0$ such that for any symmetric positive definite matrix $P_{j}(0), \exists \theta_{j} \succ \theta_{j 0}, \exists \alpha_{j}, \beta_{j}, t_{0} \succ 0: \forall t \succ t_{0}$,

$$
\forall t \succ t_{0}, \quad \alpha_{j} I \prec P_{j}(t) \prec \beta_{j} I,
$$

where I is the identity matrix.

The proof of this lemma follows the same steps of Theorem 3.2 in [24].

The system will be represented by a set of interconnected subsystems (Figure 10):

$$
\Sigma\left\{\begin{array}{l}
\dot{\chi}_{1}=A_{1}\left(S_{k}\right) \chi_{1}+\Gamma_{2}\left(S_{k}, \chi_{j}\right) \\
\dot{\chi}_{2}=A_{2}\left(S_{k}\right) \chi_{2}+\Gamma_{1}\left(S_{k}, \chi_{j}\right) .
\end{array}\right.
$$

The idea of this paper is to construct an observer for all the system $\Sigma$ from the separate observers of the subsystem $\Sigma_{j}$.

If $\varphi_{j}$ is an exponential observer for $\Sigma_{j}$, then the following interconnected system:

$$
\varphi\left\{\begin{array}{l}
\dot{\chi}_{1}=A_{1}\left(S_{k}\right) \chi_{1}+\Gamma_{1}\left(S_{k}, \chi_{j}\right)+P_{1}^{-1} C_{1}^{T}(\hat{y}-y) \\
\dot{\chi}_{2}=A_{2}\left(S_{k}\right) \chi_{2}+\Gamma_{2}\left(S_{k}, \chi_{j}\right)+P_{2}^{-1} C_{2}^{T}(\hat{y}-y) \\
P_{1}=-\theta_{1} P_{1}-A_{1}^{T}\left(S_{k}\right) P_{1}-P_{1} A_{1}\left(S_{k}\right)+C_{1} C_{1}^{T} \\
P_{2}=-\theta_{2} P_{2}-A_{2}^{T}\left(S_{k}\right) P_{2}-P_{2} A_{2}\left(S_{k}\right)+C_{2} C_{2}^{T} .
\end{array}\right.
$$

is an observer for the interconnected system $\Sigma$.

Each observer subsystem $\varphi_{j}$ is defined by (25).

Remark 2. The proposed observer functions in the case if the inputs controls are regularly persistent (see Appendix A), which is equivalent to that all subsystem $\varphi_{j}$ is observable.

Now, we give the sufficient conditions which ensure the convergence of the interconnected observer $\varphi$. For that, we introduce the following assumptions.

Assumption 1. Assume that the input $S_{j}$ is a regularly persistent input for subsystem $\Sigma_{j}$ and admits an exponential observer $\varphi_{j}$ for $j=1,2$. If an input is regularly persistent, it excites sufficiently the system to obtain information necessary to constructing the not measured variables using the designed observer (see Appendix A). In this case, an observer of the form $\varphi$ can be designed and the estimation error will be bounded.

Assumption 2. The term $\Gamma_{j}\left(S_{k}, \chi_{i}\right)$ does not destroy the observability property of subsystem $\varphi_{j}$ under the action of the regularly persistent input $S_{j}$. Moreover, $\Gamma_{j}\left(S_{k}, \chi_{i}\right)$ is Lipchitz with respect to $\chi_{i}$ and uniformly with respect to $S_{j}$ for $j=1,2$. This condition is verified because these functions are linear.

Then the following result can be established.

Lemma 3. Consider the interconnected system $\Sigma$ and the two Assumptions 1 and 2 are verified. Then the system $\varphi(30)$ is an observer for the system $\Sigma(29)$.

The proof of the lemma is given in Appendix B.

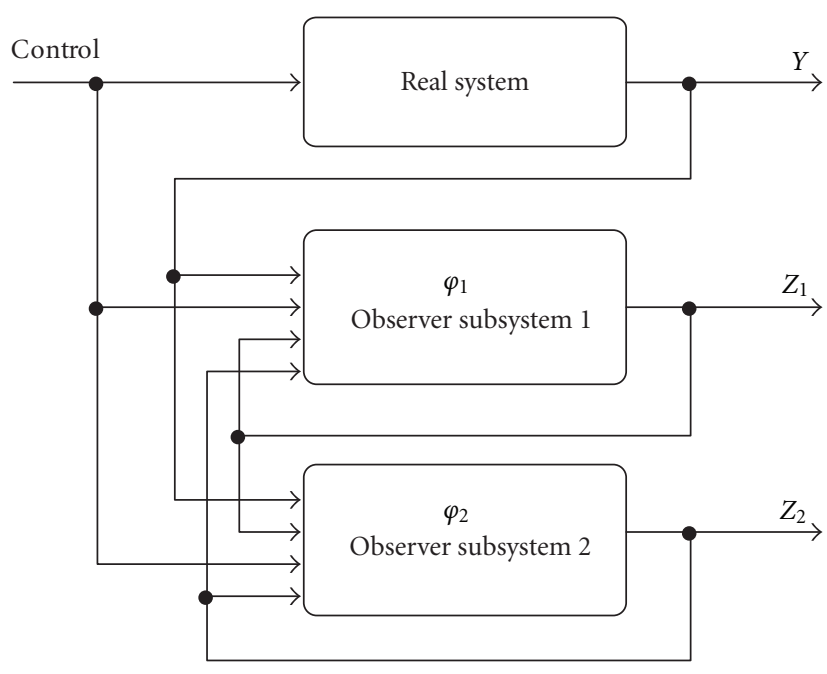

FIGURE 10: Interconnected observer diagram.

\section{Simulation Results}

In this section, a detailed simulation was carried out to validate the proposed interconnected observer. The general block diagram is shown in Figure 11. In this study the 3-level NPC inverter block was replaced by the averaged model of the inverter to develop the observer. The block of the interconnected observer is given by (30). In order to show the accuracy of the observer a fine model (circuit model) of the inverter (implemented in Matlab Simpower) was used to estimate the capacitors voltages. The estimated capacitors voltages of the two models are compared to the real capacitors voltages. We define the real capacitor voltage by the capacitor voltage given by the voltages sensors of the circuit model implemented in Simpower Matlab.

The different behavior of the interconnected observer was performed. The capacitors values are $C_{1}=C_{2}=1000 \mu \mathrm{F}$. The NPC Inverter is connected at three equilibrium phases where each phase composed by an inductor $L=10 \mathrm{mHand}$ a resistor $R=20 \Omega$. To estimate the NPC capacitor voltages according to (25) the observer parameter gain $\theta_{j}=15000$ for $j=1,2$ is used. SVPWM was used to control the multilevel inverter described in Section 2. The switching frequency was fixed at $10 \mathrm{kHz}$. Simulations were carried out using matlab/simulink. Matlab simulator is an important tool where different system models (electrical, mechanical, thermal, etc.) can be developed. In fact, Matlab simulator enables averaged model representation.

Figures 12 and 13 show the comparison between the estimated capacitors voltages $C_{1}$ and $C_{2}$ (using nonideal average model and circuit model) and the real capacitor voltage.

Figures 14 and 15 show the estimated errors for the estimated capacitors voltages $V_{C 1}$ and $V_{C 2}$. The error for each model is calculated by $\left(V_{C i}\right.$-real $)-\left(V_{C i}\right.$-estimated $)$.

In order to study the observer behavior, we changed the load of the first leg ( $L=10 \mathrm{mH}, R=20 \Omega$ ) to $(L=10 \mathrm{mH}$, $R=40 \Omega$ ) at $t=0.1 \mathrm{~s}$ (Figures 16 and 17). In other terms, 


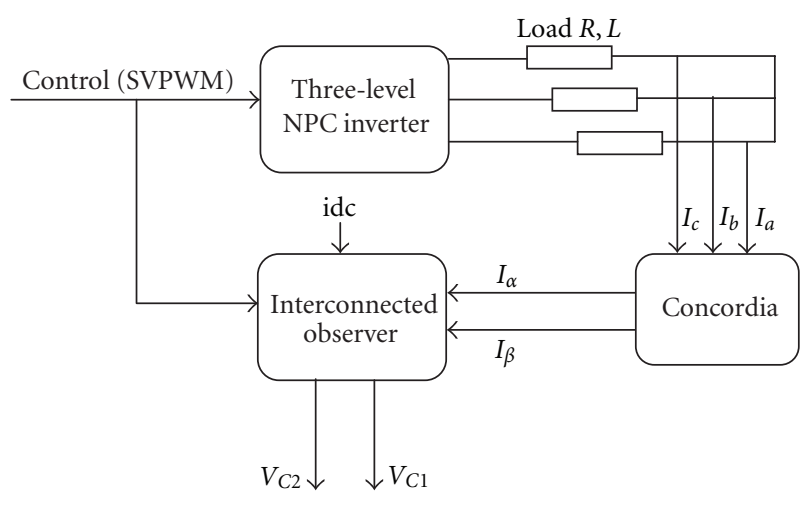

FIGURE 11: Block diagram of three-level NPC inverter and interconnected observer.

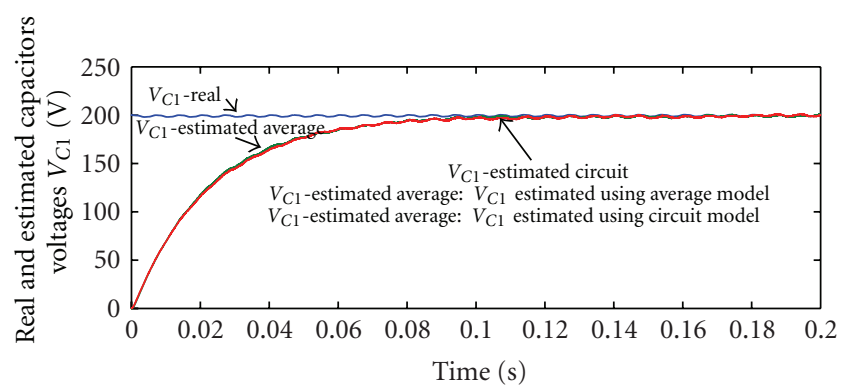

FIGURE 12: Real and estimated capacitors voltages $V_{C 1}(\mathrm{~V})$ using nonideal average model and circuit model (Simpower Matlab).

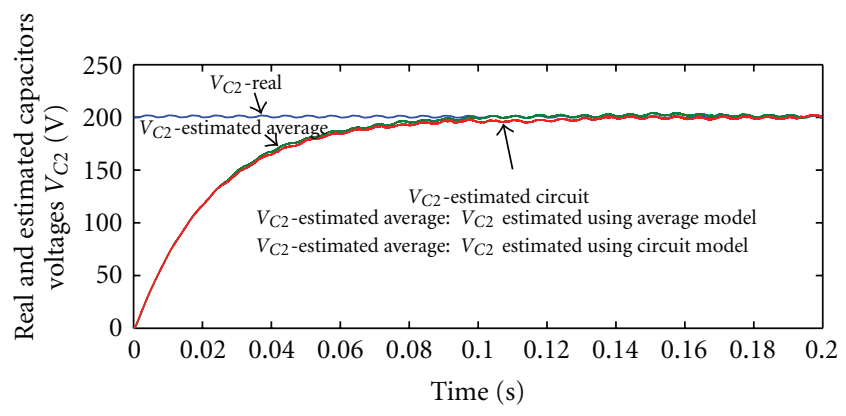

FIGURE 13: Real and estimated capacitors voltages $V_{C 2}(\mathrm{~V})$ using nonideal average model and circuit model (Simpower Matlab).

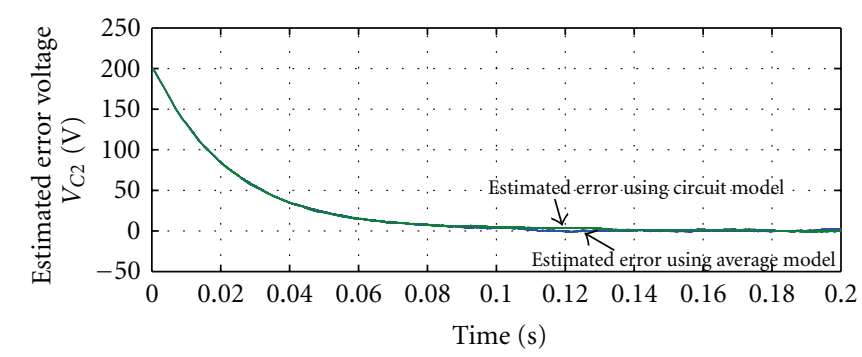

FIgURE 14: Estimation errors for $V_{C 1}(\mathrm{~V})$ using nonideal average model and circuit model (Simpower Matlab).

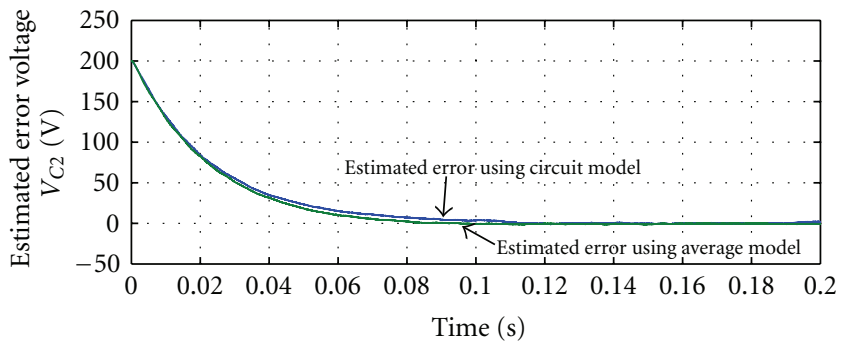

FIGURE 15: Estimation errors for $V_{C 2}(\mathrm{~V})$ using nonideal average model and circuit model (Simpower Matlab).

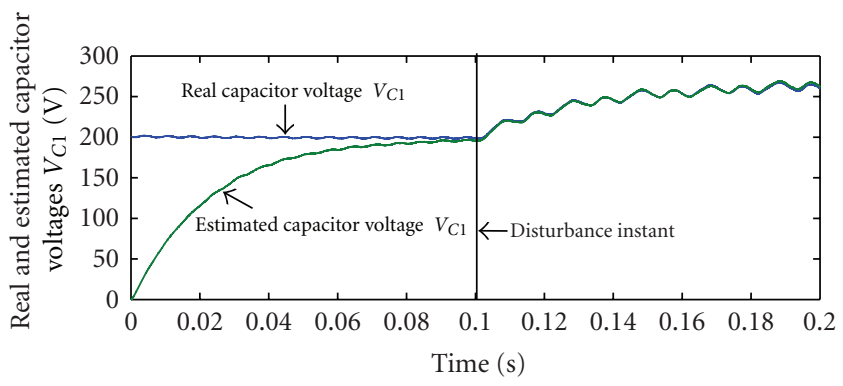

FIGURE 16: Real and estimated capacitors voltages $V_{C 1}(\mathrm{~V})$ using nonideal average model with disturbance load.

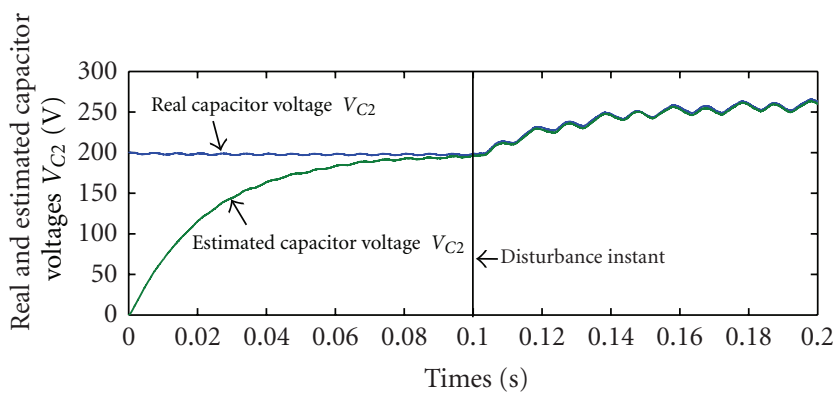

FIGURE 17: Real and estimated capacitors voltages $V_{C 2}(\mathrm{~V})$ using nonideal average model with disturbance load.

we have not got equilibrium three phases. Then, Figures 18 and 19 show at $t=0.1 \mathrm{~s}$ the change of the load of the first leg $(L=10 \mathrm{mH}, R=20 \Omega)$ to $(L=10 \mathrm{mH}, R=40 \Omega)$ and at $t=0.15 \mathrm{~s}$ we return to the initial load.

Simulations results show the usefulness of this design. In any condition, the observer is able to follow the real capacitor voltages accurately. Moreover, the good agreement between estimated capacitors voltages obtained by the proposed averaged model and the circuit model from Simpower Matlab is illustrated. We notice that simulation time with fine model (circuit model implemented in Simpower Matlab) is eight times (Table 1) greater than the simulation with the averaged model. This is an important reason to use averaged modeling especially in complex converters architecture. Converter states observer and control becomes, more and more easy. 


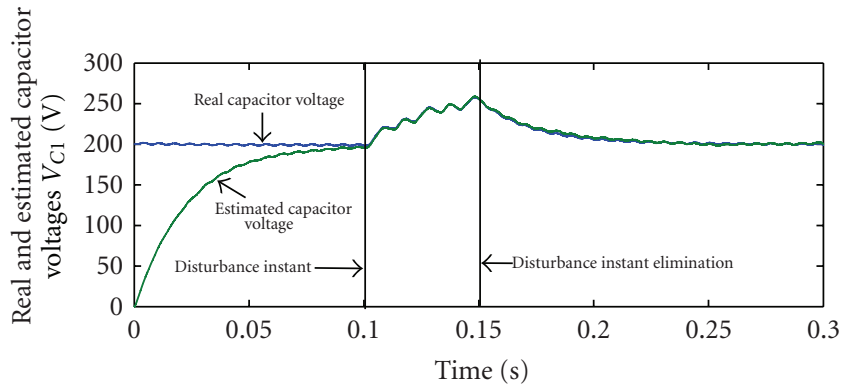

FIGURE 18: Real and estimated capacitors voltages $V_{C 1}(\mathrm{~V})$ using nonideal average model with disturbance load and its elimination.

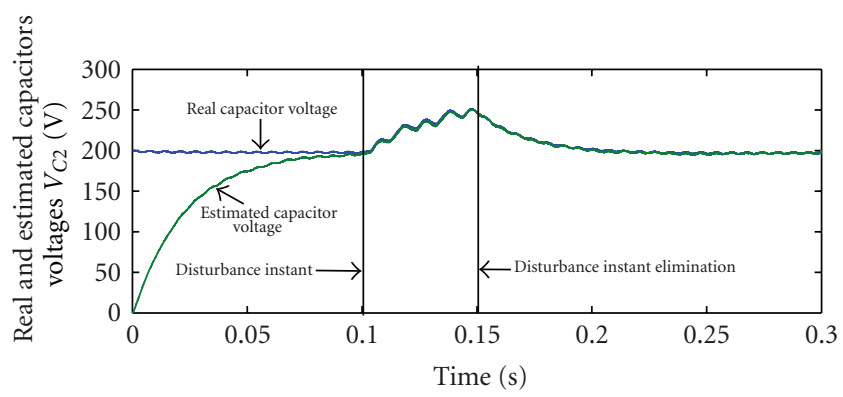

FIgURE 19: Real and estimated capacitors voltages $V_{C 2}(\mathrm{~V})$ using nonideal average model with disturbance load and its elimination.

\section{Conclusion}

The control and monitoring of the capacitors voltages in multilevel NPC converter are essential. Measuring voltages becomes expensive and impractical because of the high voltages and power levels handled in such applications. Thus the advantage of using an observation technique becomes evident.

This paper proposed an adaptive observer to estimate the capacitor voltages in NPC inverter. This observer can reconstruct the capacitor voltages accurately from the nonideal average model inputs and replace the needed capacitor voltage sensors. Simulation results show the good precision of the proposed average model. It can be used for the NPC converters analysis instead of fastidious simulations in circuit type simulators where simulations cost is unaffordable. The obtained results are acceptable, and let us conclude that the observer is well suited for purposes control of the capacitor voltages in multilevel NPC inverter.

\section{Appendices}

\section{A. Observability Definitions}

We introduce some definitions related with the inputs applied to the system. Consider a state-affine controlled system of the form

$$
\Sigma\left\{\begin{array}{l}
\dot{x}=A(u) x+B(u) \\
y=C x
\end{array}\right.
$$

where $x \in \mathbb{R}^{n}, u \in \mathbb{R}^{m}, y \in \mathbb{R}^{p}$ with $A: \mathbb{R}^{m} \rightarrow M(n, m), B$ : $\mathbb{R}^{m} \rightarrow M(n, 1)$ continuous, and $C \in M(p, n)$, where $M(k, l)$ denotes the space of $k \times l$ matrices with coefficients in $\mathbb{R} k$ (resp., $l$ ) are the number of rows (resp., columns). From now on, we will assume that $B(u)=0$ without loss of generality.

Notation. let $\varphi_{u}(\tau, t)$ denotes the transition matrix of

$$
\begin{gathered}
\frac{d}{d \tau} \varphi_{u}(\tau, t)=A(u(\tau)) x+\varphi_{u}(\tau, t), \\
\varphi_{u}(\tau, t)=I,
\end{gathered}
$$

with the classical relation $\varphi_{u}\left(t_{1}, t_{2}\right) \varphi_{u}\left(t_{2}, t_{3}\right)=\varphi_{u}\left(t_{1}, t_{3}\right)$

We then define the following:

(i) The observability gramian

$$
\Gamma(t, T, u)=\int_{t}^{t+T} \varphi_{u}^{T}(\tau, t) C^{T} C \varphi_{u}(\tau, t) d \tau .
$$

(ii) The universality index

$$
\gamma(t, T, u)=\min _{i}\left(\lambda_{i}(\Gamma(t, T, u))\right)
$$

where $\lambda_{i}(M)$ stands for the eigenvalues of a given matrix $M$. The input functions are assumed to be measurable and such that $A(u)$ is bounded on the set of admissible inputs of $\mathbb{R}^{+}$.

Now, we give definitions of regular persistence of input $u$.

Definition 4 (regular Persistence). A measurable bounded input $u$ is said to be regularly persistent for the state-affine system $(\Sigma)$ if there exists $T \succ 0, \alpha \succ 0, t_{0} \succ 0$ such that $\gamma(t, T, u) \succ 0$ for every $t \geq t_{0}$.

\section{B. Regular Persistence}

This proof is based on the demonstration in [25].

The dynamics of the estimation error $\varepsilon_{j}=Z_{j}-\chi_{j}$ is given by $\dot{\varepsilon}_{j}=\left(A\left(S_{j}\right)-P_{j}^{-1} C_{j}^{T} C_{j}\right) \varepsilon_{j}+\Delta \Gamma_{j}\left(S_{j}, \chi_{j}, Z_{j}\right)$, where $\Delta \Gamma_{j}\left(S_{j}, \chi_{j}, Z_{j}\right)=\Gamma_{j}\left(S_{j}, Z_{j}\right)-\Gamma_{j}\left(S_{j}, \chi_{j}\right)$ for $j=1,2$.

Now, let $V=V_{1}+V_{2}$ be a Lyapunov function for the interconnected system $\Sigma$, where $V_{j}\left(\varepsilon_{j}\right)=\varepsilon_{j}^{T} P_{j} \varepsilon_{j}$ is a Lyapunov function for each subsystem $\Sigma_{j}$.

From the time derivative of $V_{j}\left(\varepsilon_{j}\right)$, it follows that $\dot{V}_{j}\left(\varepsilon_{j}\right) \leq-\theta_{j} V_{j}\left(\varepsilon_{j}\right)+\varepsilon_{j}^{T} P_{j} \Delta \Gamma_{j}\left(S_{j}, \chi_{j}, Z_{j}\right)$ for $j=1,2$.

Now, adding and subtracting the term $\Delta \Gamma_{j}\left(S_{j}, \chi_{j}\right.$, $\left.Z_{j}\right)^{T} P_{j} \Delta \Gamma_{j}\left(S_{j}, \chi_{j}, Z_{j}\right)$ we have

$$
\begin{aligned}
\dot{V}_{j}\left(\varepsilon_{j}\right) \leq & -\theta_{j} V_{j}\left(\varepsilon_{j}\right)+\varepsilon_{j}^{T} P_{j} \Delta \Gamma_{j}\left(s_{j}, \chi_{j}, Z_{j}\right) \\
& \pm \Delta \Gamma_{j}\left(s_{j}, \chi_{j}, Z_{j}\right)^{T} P_{j} \Delta \Gamma_{j}\left(s_{j}, \chi_{j}, Z_{j}\right) .
\end{aligned}
$$

Next, regrouping the appropriate terms,

$$
\begin{aligned}
\dot{V}_{j}\left(\varepsilon_{j}\right) \leq & -\left(\theta_{j}-1\right)\left\|\varepsilon_{j}\right\|_{P_{j}}^{2}-\left\|\varepsilon_{j}\right\|_{P_{j}}^{2}+2 \varepsilon_{j}^{T} P_{j} \Delta \Gamma_{j}\left(S_{j}, \chi_{j}, Z_{j}\right) \\
& -\left\|\Delta \Gamma_{j}\left(S_{j}, \chi_{j}, Z_{j}\right)\right\|_{P_{j}}^{2}+\left\|\Delta \Gamma_{j}\left(S_{j}, \chi_{j}, Z_{j}\right)\right\|_{P_{j}}^{2} .
\end{aligned}
$$


From this inequality, we get $\dot{V}_{j}\left(\varepsilon_{j}\right) \leq-\left(\theta_{j}-1\right)\left\|\varepsilon_{j}\right\|_{P_{j}}^{2}+$ $\left\|\Delta \Gamma_{j}\left(S_{j}, \chi_{j}, Z_{j}\right)\right\|_{P_{j}}^{2}$.

Now, from Assumption 2, we have $\left\|\Delta \Gamma_{j}\left(S_{k}, \chi_{j}, Z_{j}\right)\right\|_{P_{k}}^{2} \leq$ $\left(\lambda_{l}\left\|\varepsilon_{l}\right\|_{P_{j}}^{2}\right)_{l \in\{1,2\} \neq j}$.

Then, we find $\dot{V}_{j}\left(\varepsilon_{j}\right) \leq-\left(\theta_{j}-1\right)\left\|\varepsilon_{j}\right\|_{P_{j}}^{2}+$ $\left(\lambda_{l}\left\|\varepsilon_{l}\right\|_{P_{j}}^{2}\right)_{l \in\{1,2\} \neq j}$.

And replacing this expression in $V=V_{1}+V_{2}$ it follows that:

$$
\dot{V}(\varepsilon) \leq \sum_{j=1}^{2}\left(-\left(\theta_{j}-1\right)\left\|\varepsilon_{j}\right\|_{P_{j}}^{2}+\left(\lambda_{l}\left\|\varepsilon_{l}\right\|_{P_{j}}^{2}\right)_{l \in\{1,2\} \neq j}\right) .
$$

Take into account that the inputs are regularly persistent, and then from Lemma 1 the matrix $P_{j}$ is bounded. Using the lemma on equivalence of norms, that is, there exists a positive constant $\mu_{l}$ such that

$$
\left\|\varepsilon_{l}\right\|_{P_{j}}^{2} \leq \mu_{l}\left\|\varepsilon_{l}\right\|_{P_{l}}^{2} .
$$

Then, we get

$$
\dot{V}(\varepsilon) \leq \sum_{j=1}^{2}\left(-\left(\theta_{j}-1\right)\left\|\varepsilon_{j}\right\|_{P_{j}}^{2}+\left(\lambda_{l}\left\|\varepsilon_{l}\right\|_{P l}^{2}\right)_{l \in\{1,2\} \neq j}\right) \text {. }
$$

or

$$
\dot{V}_{j}\left(\varepsilon_{j}\right) \leq-\sum_{j=1}^{2}\left(\left(\theta_{j}-1\right)-\mu_{l} \lambda_{l}\right)\left\|\varepsilon_{j}\right\|_{P_{j}}^{2}
$$

Finally, we have

$$
\dot{V}\left(\varepsilon_{j}\right) \leq V(\varepsilon(t)) e^{-\gamma\left(t-t_{0}\right)} .
$$

For $\gamma=\min \left(\gamma_{1}, \gamma_{2}\right)$, where $\gamma_{j}=\left(\theta_{j}-1\right)-\mu_{j} \lambda_{j}$, taking $\varepsilon=\operatorname{col}\left(\varepsilon_{1}, \varepsilon_{2}\right)$, it is easy to see that

$$
\|\varepsilon(t)\| \leq K\left\|\varepsilon\left(t_{0}\right)\right\| e^{-\gamma\left(t-t_{0}\right)} .
$$

\section{References}

[1] G. Baoming and F. Z. Peng, "Speed sensorless vector control induction motor drives fed by cascaded neutral point clamped inverter," in Proceedings of the 24th Annual IEEE Applied Power Electronics Conference and Exposition (APEC '09), pp. 19911997, February 2009.

[2] B. Hu, G. Xu, M. Zhang, J. Kang, and L. Xia, "Study on a novel clamped topology of multilevel converters," in Proceedings of the IEEE International Electric Machines and Drives Conference (IEMDC '09), pp. 379-384, May 2009.

[3] T. A. Lipo, M. D. Manjrekar, and P. Steimer, "Hybrid multilevel power conversion system: a competitive solution for high power applications," in Proceedings of the 34th IEEE-IAS Annual Meeting, pp. 1520-1527, October 1999.

[4] O. Vodyakho and C. C. Mi, "Three-level inverter-based shunt active power filter in three-phase three-wire and four-wire systems," IEEE Transactions on Power Electronics, vol. 24, no. 5, pp. 1350-1363, 20089.

[5] F. J. C. Padilha, W. I. Suemitsu, M. D. Bellar, and P. M. Lourenco, "Low-cost gate drive circuit for three-level neutralpoint-clamped voltage-source inverter," IEEE Transactions on Industrial Electronics, vol. 56, no. 4, pp. 1196-1204, 2009.
[6] T. Wanjekeche, D. V. Nicolae, and A. A. Jimoh, "A cascaded NPC/H-bridge inverter with simplified control strategy and minimum component count," in Proceedings of the IEEE Africon, vol. 4, pp. 769-777, September 2009.

[7] R. P. Aguilera and D. E. Quevedo, "Capacitor voltage estimation for predictive control algorithm of flying capacitor converters," in Proceedings of the IEEE International Conference on Industrial Technology (ICIT '09), pp. 1-6, February 2009.

[8] T. A. Meynard, H. Foch, P. Thomas, J. Courault, R. Jakob, and M. Nahrstaedt, "Multicell converters: basic concepts and industry applications," IEEE Transactions on Industrial Electronics, vol. 49, no. 5, pp. 955-964, 2002.

[9] E. Babaei, "A cascade multilevel converter topology with reduced number of switches," IEEE Transactions on Power Electronics, vol. 23, no. 6, pp. 2657-2664, 2008.

[10] A. Nabae, I. Takahashi, and H. Akagi, "A neutral-point clamped PWM inverter," in Proceedings of the IEEE-IAS, pp. 761-766, October 1981.

[11] H. Zhang, S. J. Finney, A. Massoud, and B. W. Williams, "An SVM algorithm to balance the capacitor voltages of the threelevel NPC active power filter," IEEE Transactions on Power Electronics, vol. 23, no. 6, pp. 2694-2702, 2008.

[12] J. A. Ulrich and A. R. Bendre, "Floating capacitor voltage regulation in diode clamped hybrid multilevel converters," in Proceedings of the IEEE Electric Ship Technologies Symposium (ESTS '09), pp. 197-202, April 2009.

[13] Y. S. Lai, Y. K. Chou, and S. Y. Pai, "Simple PWM technique of capacitor voltage balance for three-level inverter with DClink voltage sensor only," in Proceedings of the 33rd Annual Conference of the IEEE Industrial Electronics Society (IECON '07), pp. 1749-1754, November 2007.

[14] A. Birouche, Contribution sur la synthèse d'observateurs pour les systèmes dynamiques hybrides [Thèse de doctorat], Institut National de Polytechnique de Lorraine, Loraine, France, 2006.

[15] S. Bonnabel and P. Rouchon, "Control and observer design for nonlinear finite and infinite dimensional systems," in Lecture Notes in Control and Information Sciences, vol. 322, pp. 53-65, Springer, 2005.

[16] M. Morari, A. Bemporad, and G. Ferrari-Trecate, "Observability and controllability of piecewise affine and hybrid systems," IEEE Transactions on Automatic Control, vol. 45, no. 10, pp. 1864-1876, 2000.

[17] H. Nademi, A. Das, and L. Norum, "Nonlinear observerbased capacitor voltage estimation for sliding mode current controller in NPC multilevel converters," in Proceedings of the IEEE Trondheim PowerTech, pp. 1-7, 2011.

[18] A. Gopinath, A. A. S. Mohamed, and M. R. Baiju, "Fractal based space vector PWM for multilevel inverters-a novel approach," IEEE Transactions on Industrial Electronics, vol. 56, no. 4, pp. 1230-1237, 2009.

[19] M. A. Trabelsi, "Modélisation et Commande des Systèmes Physiques à Topologie Variable: Application au Convertisseur Multicellulaire," L'Institut National des Sciences Appliquées de Lyon, 2009.

[20] J. Chen, R. Erickson, and D. Maksimović, "Averaged switch modeling of boundary conduction mode dc-to-dc converters," in Proceedings of the 27th Annual Conference of the IEEE Industrial Electronics Society (IECON '2001), pp. 844-849, December 2001.

[21] B. Urmila and D. Subba Rayudu, "Optimum space vector PWM algorithm for three-level inverter," ARPN Journal of Engineering and Applied Sciences, vol. 6, no. 9, pp. 24-36, 2011.

[22] K. Ammous, E. Haouas, and S. Abid, "Averaged modelling of multilevel converters," The International Journal for 
Computation and Mathematics in Electrical and Electronic Engineering, vol. 29, no. 3, pp. 626-646, 2010.

[23] V. Andrieu, L. Praly, and A. Astolfi, "High gain observers with updated gain and homogeneous correction terms," Automatica, vol. 45, no. 2, pp. 422-428, 2009.

[24] H. Khalil, Nonlinear Systems, Prentice-Hall, 2nd edition, 1996.

[25] J. De León Morales, M. F. Escalante, and M. T. Mata-Jiménez, "Observer for DC voltages in a cascaded H-bridge multilevel STATCOM," IET Electric Power Applications, vol. 1, no. 6, pp. 879-889, 2007. 

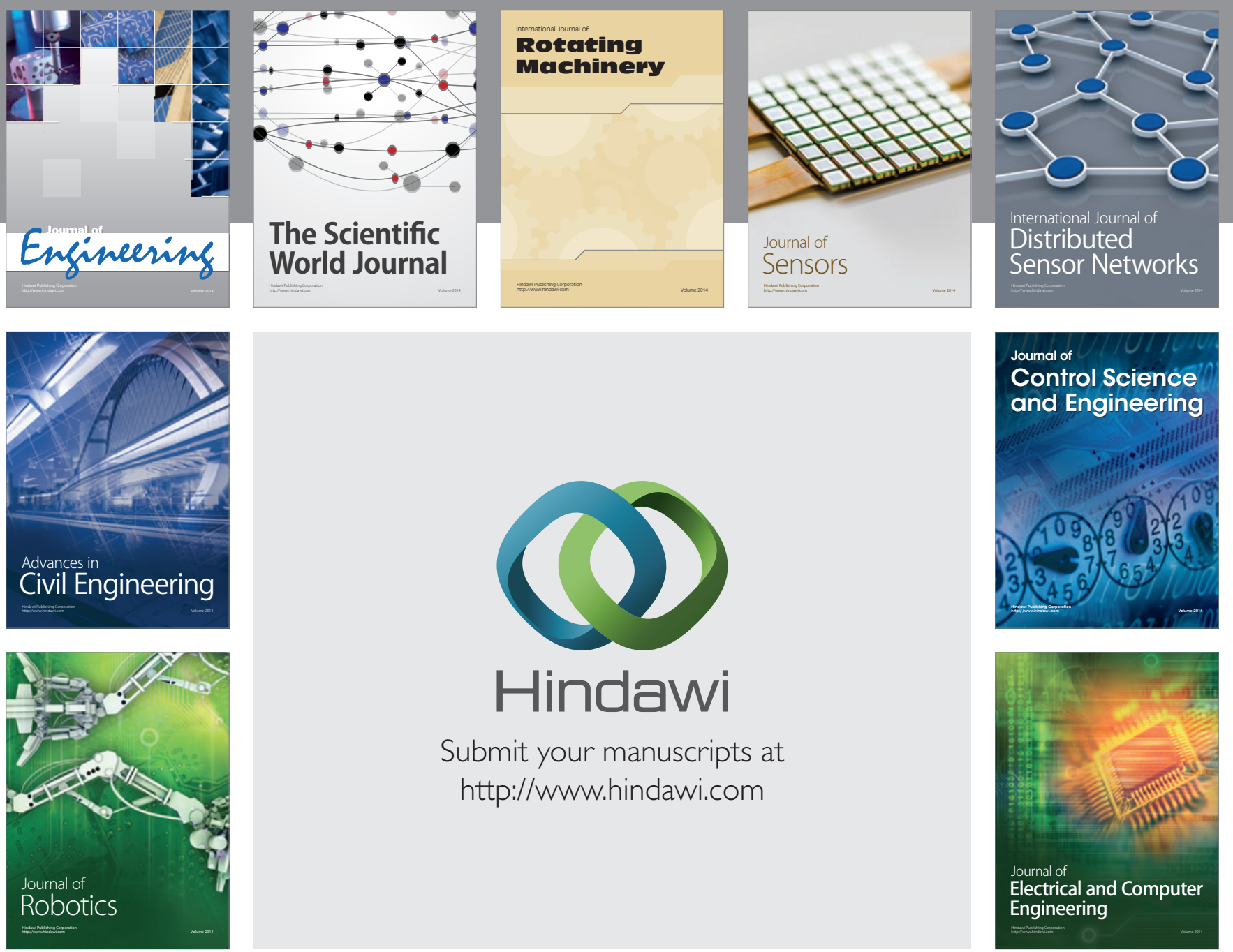

Submit your manuscripts at

http://www.hindawi.com
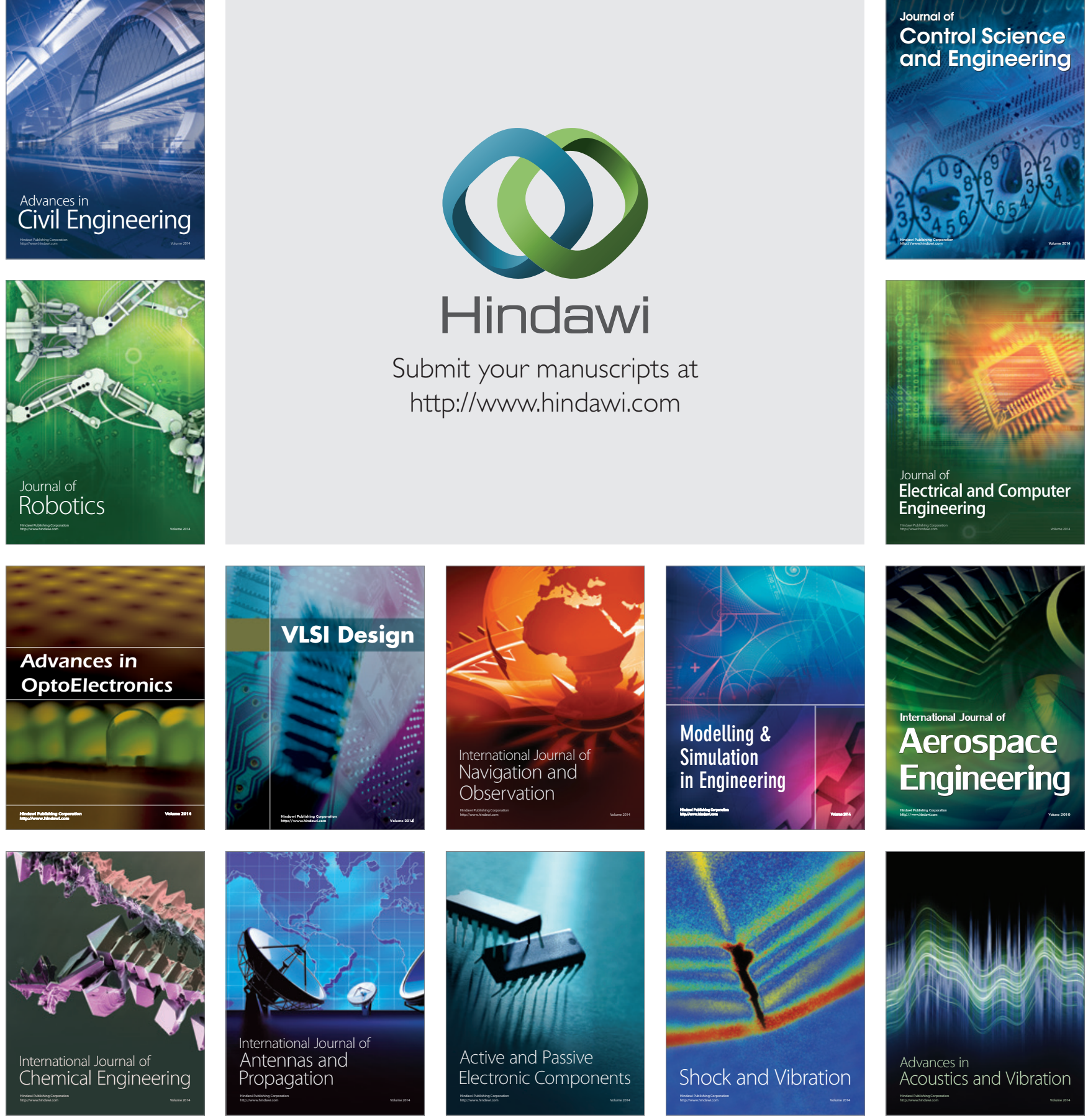